\title{
OPTIMIZED LOGISTICS FOR SLAB STORAGE AT ARCELOR MITTAL IN GERMANY*
}

Rene Grabowski ${ }^{1}$

\begin{abstract}
Optimization of workflows and intelligent stock management; Slab stacking improvement by automated transport orders; and System automatically registers any slab movements even in manual operation. Case story: Steel producer ArcelorMittal Eisenhüttenstadt GmbH in Germany uses Primetals Technologie's new stock yard logistics system in its finishing department. An exact image of its slab storage at any times is given by the warehouse logistics system to the company. It not only enhances the composition of the stacks of slabs, but also automates recording of manual restacking operations. Therefore the solution improves workflows and simplifies stock control. Cycle times have also been reduced due to the fact that the slabs can be charged to reheating furnaces ahead of the rolling mill due to less restacking operations within the slab storage. The expandable, modular system is based on the Siemens Simatic IT and Primetals Technologies' IT4METALS Logistics product platform. It provides a large number of organizational and commercial features in the form of sophisticated graphics and tabular evaluations. For example, it can show how many crane movements have been made per shift for any category of slab, so that the time and cost for each operation can be calculated accurately.

Keywords: Warehouse; Stock management; Slab; Plate; Sheet yard; IT solution; Level 3; IT4METALS; Inventory system; software; Transport order management; Supply chain.
\end{abstract}




\section{INTRODUCTION}

Logistical operations at steel plants - particularly in the downstream finishing area have a direct impact on overall production efficiency and profitability. As part of a plant-wide modernization program, the IT4METALS Logistics storage system was installed at the integrated steelworks of ArcelorMittal Eisenhüttenstadt $\mathrm{GmbH}$ in Germany. The resulting benefits include optimized material workflows, simplified stock control and shorter manufacturing cycle times.

\section{OPTIMIZED STORAGE LOGISTICS}

ArcelorMittal Eisenhüttenstadt is an important European supplier of high-quality, coated and uncoated flat steel products for the automotive, domestic appliance and construction industries. In the company's finishing area, slabs are accepted, inspected, scarfed, transported, and stored according to scheduling and quality specifications. According to the production schedule, slabs are then selected and transferred to the hot-rolling mill. This is followed by inspection and finishing of the rolled products and prepared for dispatch. The plant personnel has to constantly coordinate the movement of twelve cranes, various storage areas, and the ongoing activities at numerous roller tables, trolleys, inspection tables, and at the slitting and cross-cutting stations. Before the IT4METALS Logistics system was installed, planning and slab stacking in the finishing area was done manually and independently of the higher-level production scheduling. The result: costly and timeconsuming restacking of products in all storage areas.

\section{LOGICAL AND LUCRATIVE LOGISTICS}

To improve the existing logistics and storage situation at its steelworks, ArcelorMittal Eisenhüttenstadt placed an order with Primetals Technologies for the installation of the new IT4METALS Logistics system. This process-optimization solution receives its input data from the higher-level production planning system (PPS), the materialtracking system (MTS) and the dispatch system. IT4METALS Logistics coordinates the work of the individual systems in the finishing area according to the slab quality parameters and disposition instructions of the received material. For example, the crane operator receives automatically generated transport orders on his cab terminal. This enables him to stack slabs in an ideal sequence on the basis of their composition and the order processing schedule. IT4METALS Logistics applies its own safety rules to secure the stability and arrangement of the stacked slabs and to protect the slabs from impact or stacking damage. The crane operator can also perform unscheduled restacking operations manually. Slab restacking movements are automatically registered by the system and entered into the database. The stored information is therefore always up to date, and all material movements can be visualized and accounted for.

The heart of the expandable and modular logistics system is the Simatic IT and IT4METALS Logistics product platform. It provides a large number of organizational and commercial metrics in the form of clear graphics and tabular evaluations. For example, it can show how many crane movements have been made per shift for any category of slab, so that the time and cost for each operation can be exactly calculated. 


\section{SIGNIFICANTLY IMPROVED OPERATIONS}

The IT4METALS Logistics system now provides ArcelorMittal Eisenhüttenstadt with a precise overview of its stock at all times, including the more than 40,000 slabs that pass through the slab storage area each year. The system not only optimizes the sequence of the stacked slabs according to their composition, it also automates logging of manual restacking operations. IT4METALS Logistics thus improves workflows and simplifies stock control. Cycle times are also reduced because the slabs can be charged to the hot-rolling mills at a higher temperature.

Dr. Ralf Bösler, Primary CEO at ArcelorMittal Eisenhüttenstadt, explained, "The new system, above all, meets future requirements for the planned modification and optimization of the technological and logistic processes in our company. The advanced strategies for storing and retrieving the slabs provide a good basis for this". As a confirmation of the success of the installed system, in April 2014 ArcelorMittal Eisenhüttenstadt issued the Final Acceptance Certificate for the new IT4METALS Logistics system from Primetals Technologies.

\section{TABLES AND FIGURES}

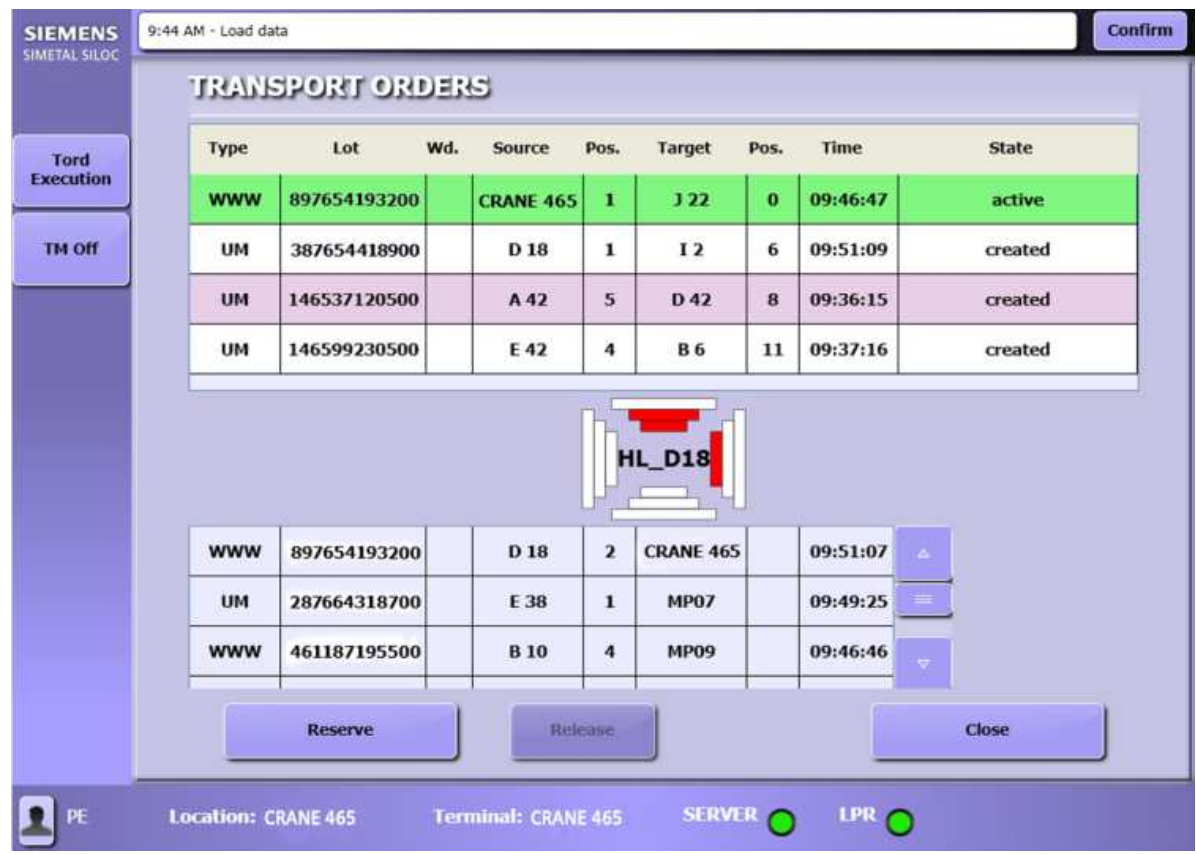

Figure 1: Navigation support for crane operators: the bar icons in the center indicate the current location of the crane. They are used to navigate to the center of the location and disappear when the crane is centered. ArcelorMittal Eisenhüttenstadt uses the IT4Metals logistics storage system in its finishing department. 


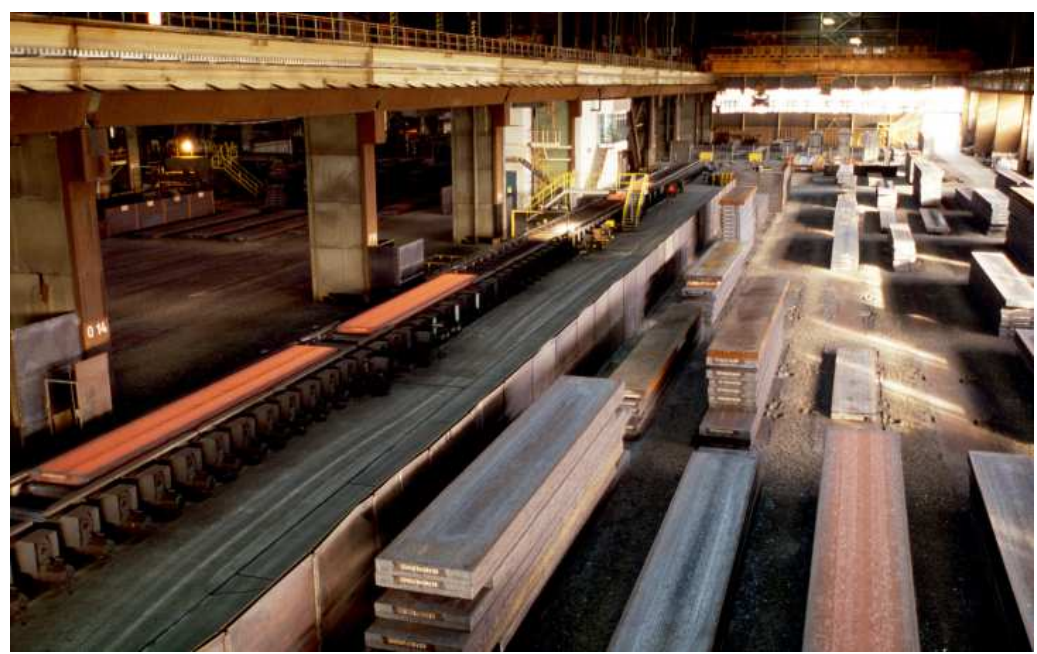

Figure 2: Slab storage area at arcelormittal eisenhüttenstadt, germany

\section{CONCLUSION}

ArcelorMittal Eisenhüttenstadt profits from the IT4METALS Logistics system. Main benefits:

- Optimized production workflows and simplified stock control: resulting from an ideal product scheduling that ensures a continuous flow of slabs from the slab casters to the finished product storage area

- Reduced manual stacking operations: thanks to automated transport orders and clear operator stacking instructions that enable the sequence of the stacked slabs to be optimized according to their composition and production planning

- Total transparency guaranteed: due to the availability of a large number of individual key performance indicators as self-explaining diagrams and statistical reports.

\subsection{Abbreviations}

\begin{tabular}{|l|l|}
\hline Abbreviation & Explanation \\
\hline APS & Advanced Planning System \\
\hline BOM & Bill of Materials \\
\hline ERP & Enterprise Resource Planning \\
\hline FIFO & First in First Out \\
\hline LIFO & Last In First Out \\
\hline SCM & Supply Chain Management \\
\hline TMS & Transportation Management System \\
\hline TQM & Total Quality Management \\
\hline WIP & Work in Process \\
\hline WMS & Warehouse Management System \\
\hline
\end{tabular}

Further information about solutions for steel works, rolling mills and processing lines can be found at http://www.Primetals.com/ or www.siemens.com/metals. 